\title{
Correction to: The role of the gut-brain axis in depression: endocrine, neural, and immune pathways
}

\author{
Anastasios P. Makris ${ }^{1}$ - Minois Karianaki ${ }^{1} \cdot$ Konstantinos I. Tsamis $^{1,2} \cdot$ Stavroula A. Paschou $^{1,3}$ (D) \\ Published online: 11 December 2020 \\ (C) Hellenic Endocrine Society 2020
}

\section{Correction to: Hormones} https://doi.org/10.1007/s42000-020-00236-4

The original version of this article, published on 21 August 2020, unfortunately contained several mistakes. The following corrections have therefore been made in the original: The explanation of the acronym "BBB" blood-brain barrier in the caption of Figure 2 was missing.

Correction of references [33], [36], [40], [50], [67], [77], and [81]
The presentation of Figure 1 was incorrect; the correct figure is given below.

The original article has been corrected.

Publisher's note Springer Nature remains neutral with regard to jurisdictional claims in published maps and institutional affiliations.

The online version of the original article can be found at https://doi.org/ 10.1007/s42000-020-00236-4

Stavroula A. Paschou

s.a.paschou@gmail.com

1 School of Medicine, European University Cyprus, Nicosia, Cyprus

2 School of Medicine, University of Ioannina, Ioannina, Greece

3 School of Medicine, National and Kapodistrian University of Athens, Athens, Greece 


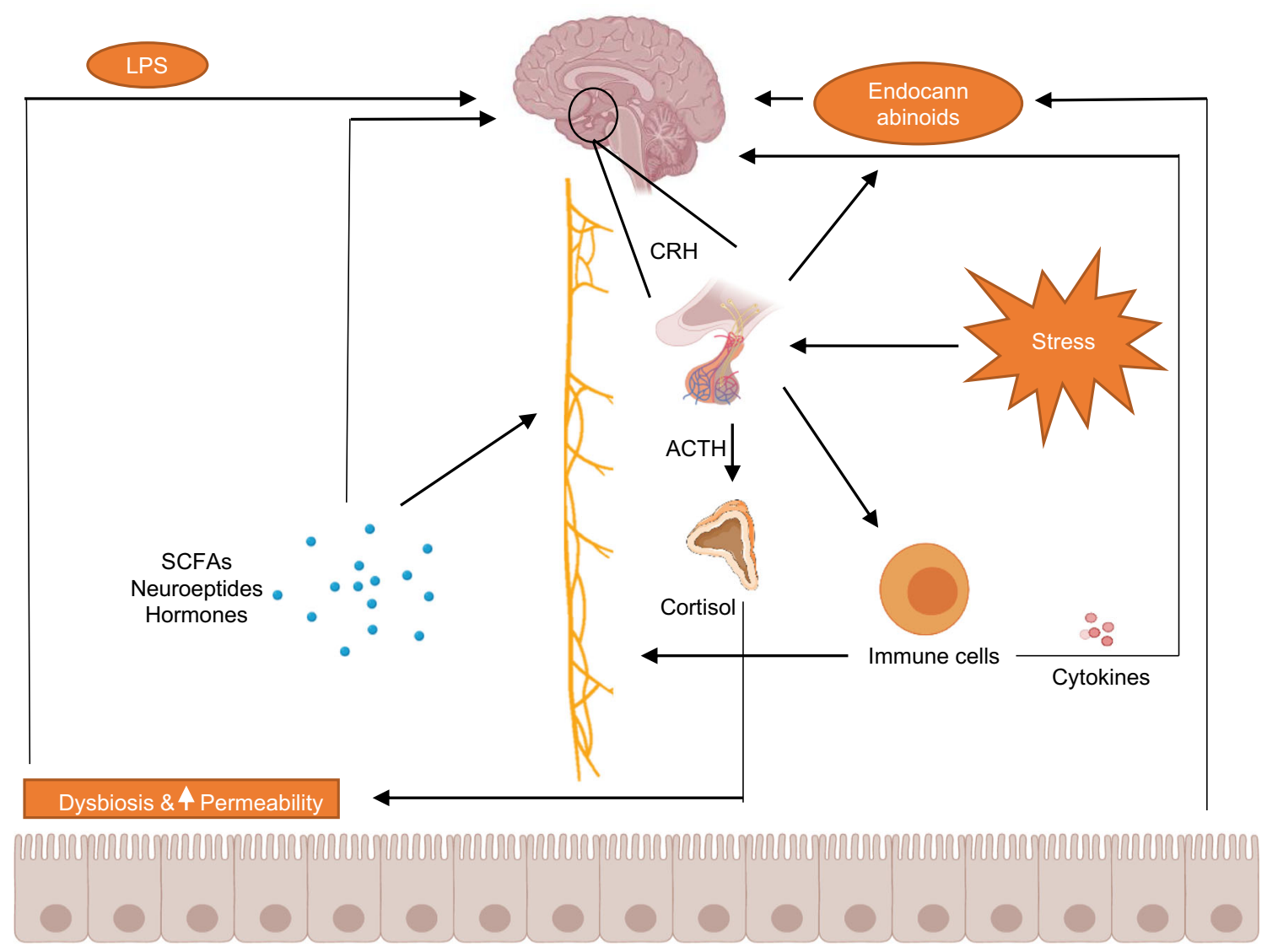

